\title{
Determination of polycyclic aromatic hydrocarbons in grilled meat.
}

\begin{abstract}
Polycyclic aromatic hydrocarbons (PAHs) are primarily formed as a result of thermal treatment of food, especially grilling or barbecuing. In this study nine types of Malaysian popular grilled meat dishes were analyzed for toxic PAHs, i.e. fluoranthene, benzo(b)fluoranthene and benzo(a)pyrene using HPLC-FD. The differences in PAH concentrations among (charcoal, gas and oven grilling) were found to be significant ( $\mathrm{p}<$ 0.05), ranging from 3.51 to $106 \mathrm{ng} / \mathrm{g}$. Fluoranthene was found in all samples; the highest concentration of total PAHs was $132 \mathrm{ng} / \mathrm{g}$ found in beef satay and the lowest was $3.51 \mathrm{ng} / \mathrm{g}$ in oven grilled chicken.
\end{abstract}

Keyword: Polycyclic aromatic hydrocarbons (PAHs); Grilled meat; Carcinogen. 